\title{
The Modeling of the Wind System and Contribution to the Control of Doubly-Fed Induction Generator with using Fuzzy Logic
}

\author{
Fatima Ezzahra Bounifli \\ Energy and electrical systems laboratory \\ Ensem, Casablanca, Morocco \\ Aicha Wahabi \\ Energy and electrical systems laboratory \\ Ensem, Casablanca, Morocco \\ Abdelhadi Elmoudden \\ Energy and electrical systems laboratory \\ Ensem, Casablanca, Morocco
}

\begin{abstract}
The aim of this work is to compare the control by using a fuzzy logic with the vector control and then to analyze the behavior of the wind turbine using a Doubly-Fed Induction Generator (DFIG). The simulation results obtained when applying the technique based on fuzzy logic, show that the performance of the control is acceptable. According to these results, the technique based on fuzzy logic can be considered as a reasonable solution for the optimization of energy conversion in wind systems because it offers a great possibility to avoid technical or economies problems.
\end{abstract}

Keywords - DFIG, fuzzy logic, optimization, energy, wind system

\section{INTRODUCTION}

The development and use of renewable energy have experienced strong growth in recent years. These sources of energy, wind generators have a special place.

Interest in the Doubly-Fed Induction Generator (DFIG) is increasing especially in the field of renewable energy. The use of (DFIG) allows the decoupled control of active and reactive power, reducing losses and the quality of the power produced. However, the (DFIG) is subject to many constraints, such as the disruption of the variation of wind speed, which could divert the system from its optimal operation. This is why the check should be concerned about the robustness and performance.

Many different structure and control algorithm can be used to control power converters. One of the most common control techniques is the active and reactive power decoupled by classical regulator: proportional and integrator (PI) to improve dynamic behavior of wind turbines.

Nevertheless, uncertainty about the exact model and behavior of some parameters such as wind, and variation of parameter values, are the main problems in the PI control method.

Using fuzzy control, we can produce controller outputs more reliable. [1]

In this article, we begin by modeling and simulation the wind turbine system. We will then analyze and compare the performance of the chain before and after the addition of an RLC filter. In addition, we analyze the dynamic performance by simulations in Matlab /Simulink /SimPowerSystems.

\section{WIND TURBINE SYSTEMS}

A. Modeling and simulation of asynchronous generator -

The Doubly-Fed Induction Generator is modeled in the benchmark park by the following equations [2, 3, 5, 6, 7, 9, 10, 11]: 


$$
\begin{aligned}
& \mathrm{v}_{\mathrm{d} s}=\mathrm{R}_{\mathrm{s}} \mathrm{i}_{\mathrm{ds}}+\frac{\mathrm{d}}{\mathrm{dt}} \emptyset_{\mathrm{ds}}-\omega_{\mathrm{s}} \emptyset_{\mathrm{q} s} \\
& v_{\mathrm{q} s}=\mathrm{R}_{\mathrm{s}} \mathrm{i}_{\mathrm{q} s}+\frac{\mathrm{d}}{\mathrm{dt}} \emptyset_{\mathrm{ds}}+\omega_{s} \emptyset_{\mathrm{ds}} \\
& v_{\mathrm{dr}}=\mathrm{R}_{\mathrm{r}} \mathrm{i}_{\mathrm{dr}}+\frac{\mathrm{d}}{\mathrm{dt}} \emptyset_{\mathrm{dr}}-\omega_{\mathrm{r}} \emptyset_{\mathrm{qr}} \\
& v_{\mathrm{qr}}=\mathrm{R}_{\mathrm{r}} \mathrm{i}_{\mathrm{qs}}+\frac{\mathrm{d}}{\mathrm{dt}} \emptyset_{\mathrm{qr}}+\omega_{\mathrm{g}} \emptyset_{\mathrm{dr}} \\
& \text { Where } \\
& \omega_{\mathrm{r}}=\omega_{\mathrm{r}}-\mathrm{p} \Omega \\
& \emptyset_{d s}=L_{s} i_{d s}+M i_{d r} \\
& \emptyset_{q s}=L_{g} i_{q s}+M i_{q r} \\
& \emptyset_{d r}=L_{y} i_{d y}+M i_{d g} \\
& \emptyset_{q r}=L_{y} i_{q r}+M i_{q s} \\
& L_{g}=l_{g}-M_{g} \\
& L_{y}=l_{r}-M_{y}
\end{aligned}
$$

B. Modeling and simulation of complete chain conversion -

A total schema of a wind energy conversion system connected to the electrical power grid is shown in (Figure1).

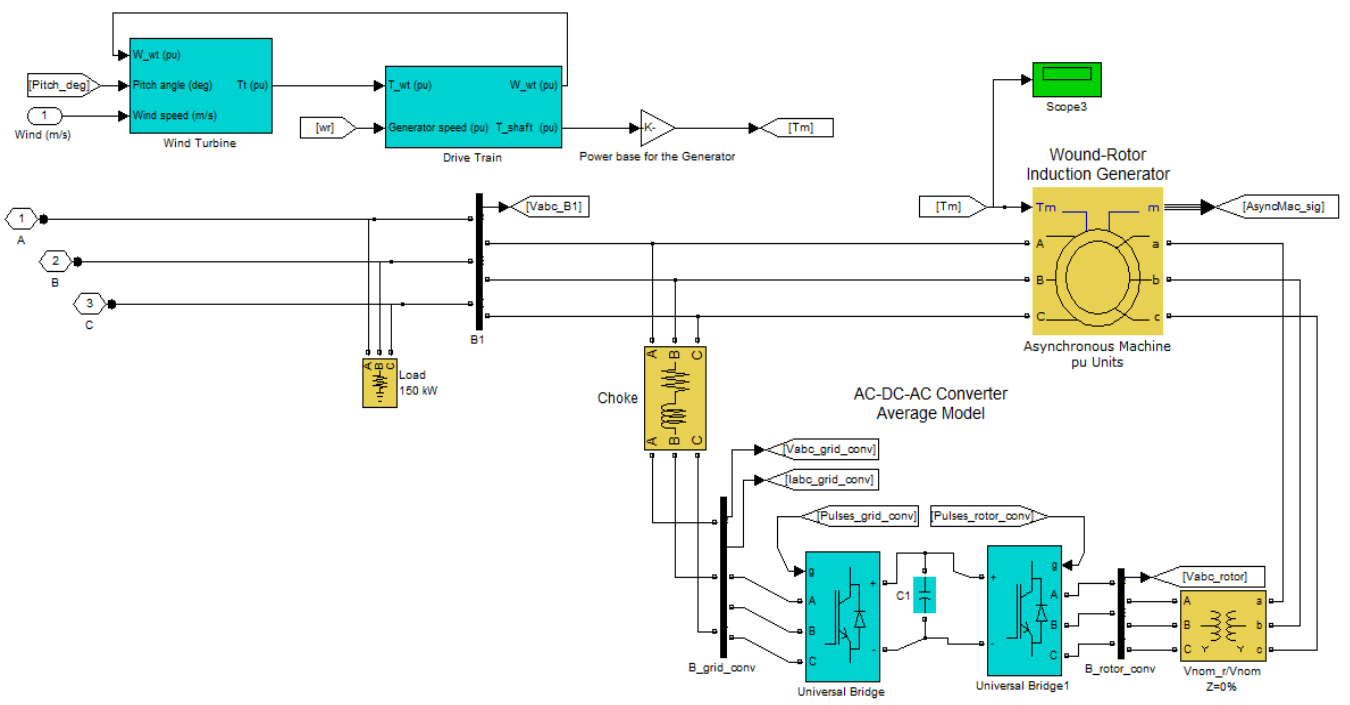

Figure 1. Wind energy conversion system based DFIG with a filter

Result of simulation: 


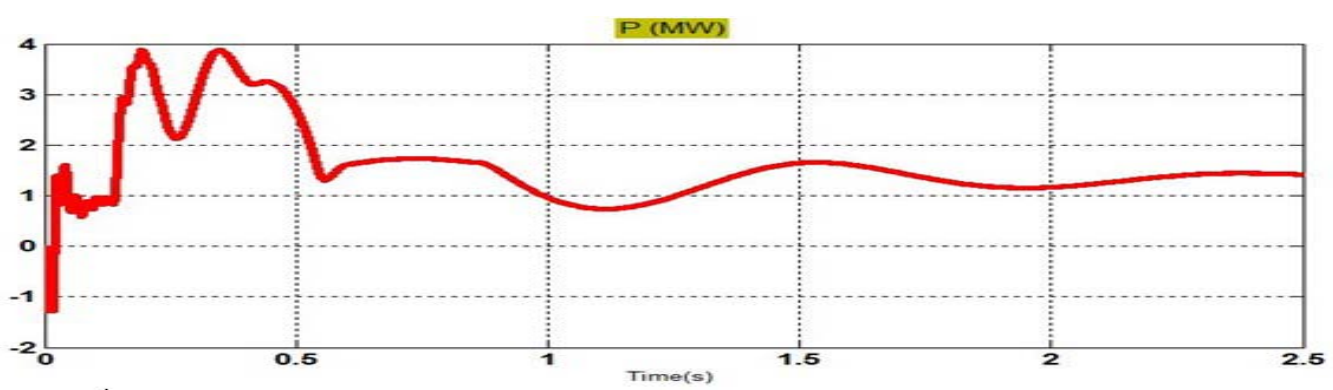

Figure 2. Active power of wind turbine

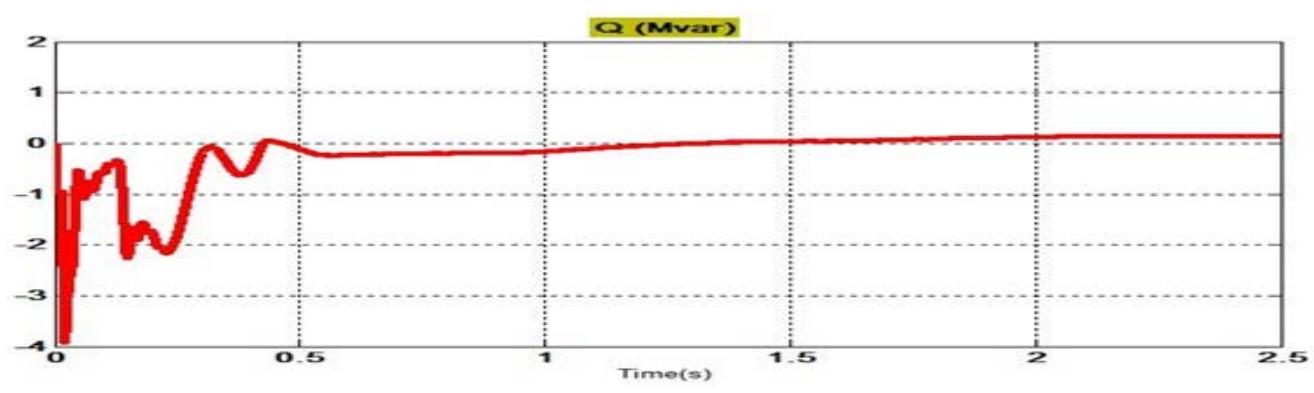

Figure 3. Reactive power of wind turbine

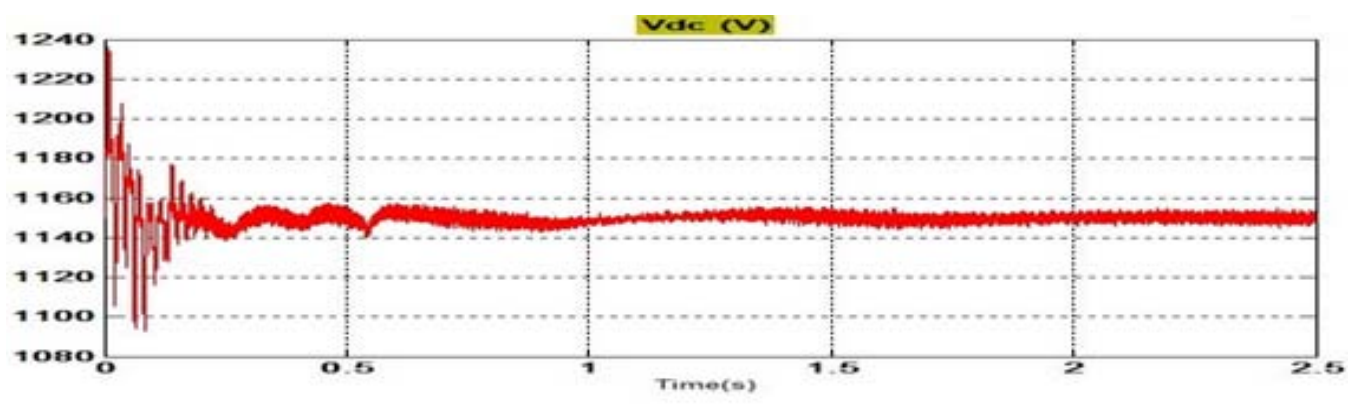

Figure 4. DC link voltage (pu) of wind turbine

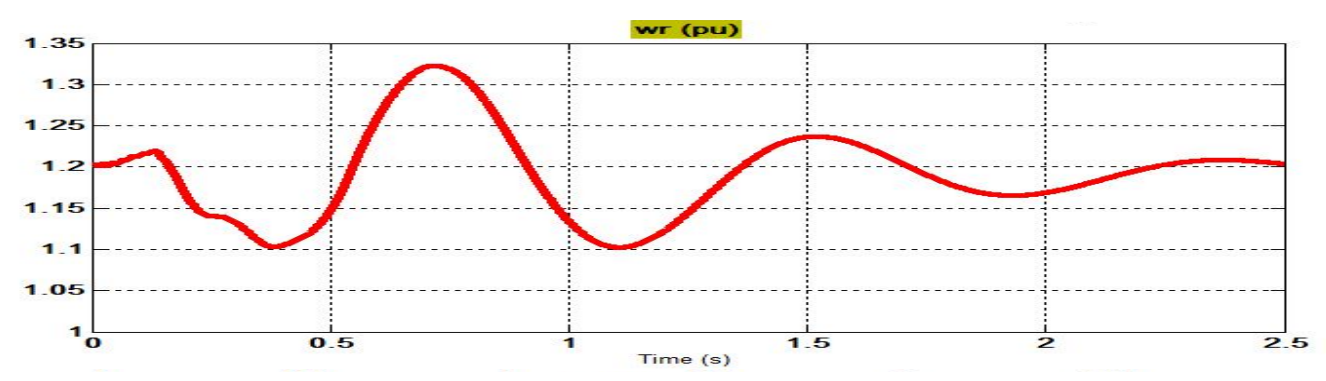

Figure 5. Rotor speed (pu) of wind turbine 


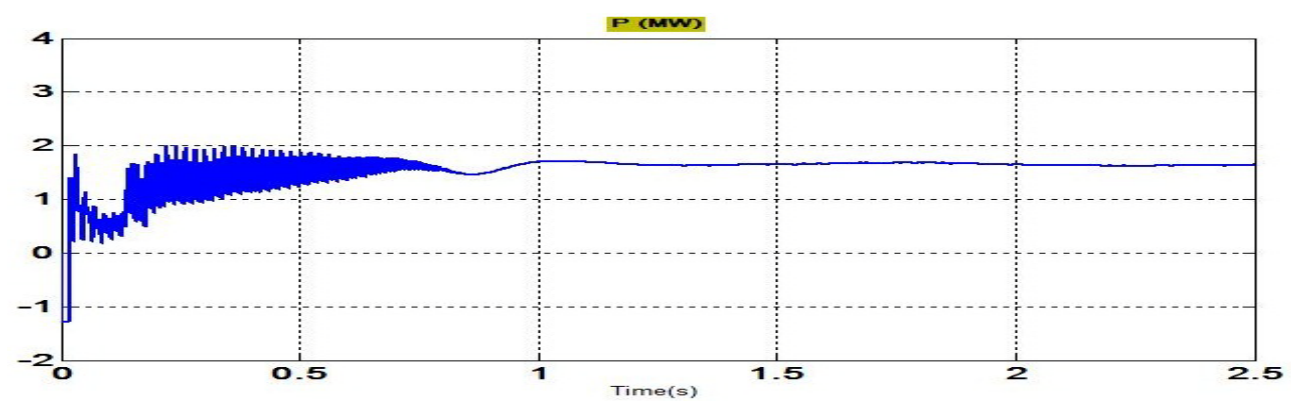

Figure 6. Active power of wind turbine without filter

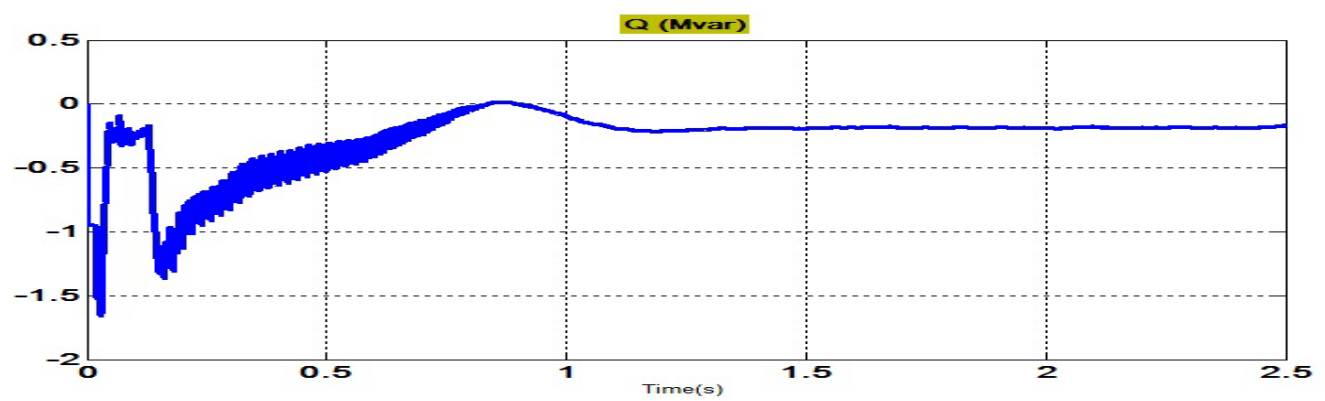

Figure 7. Reactive power of wind turbine without filter

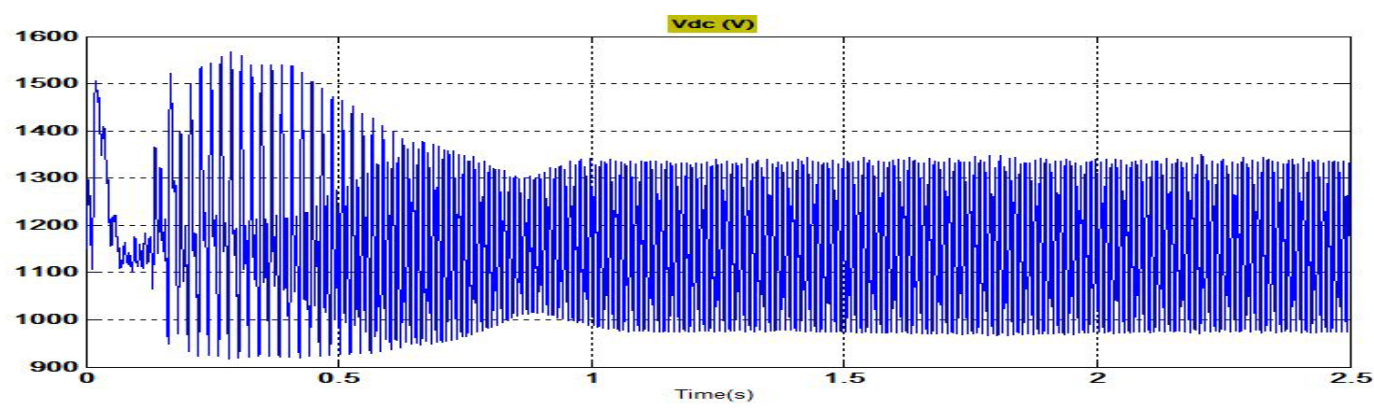

Figure 8. DC link voltage (pu) without filter

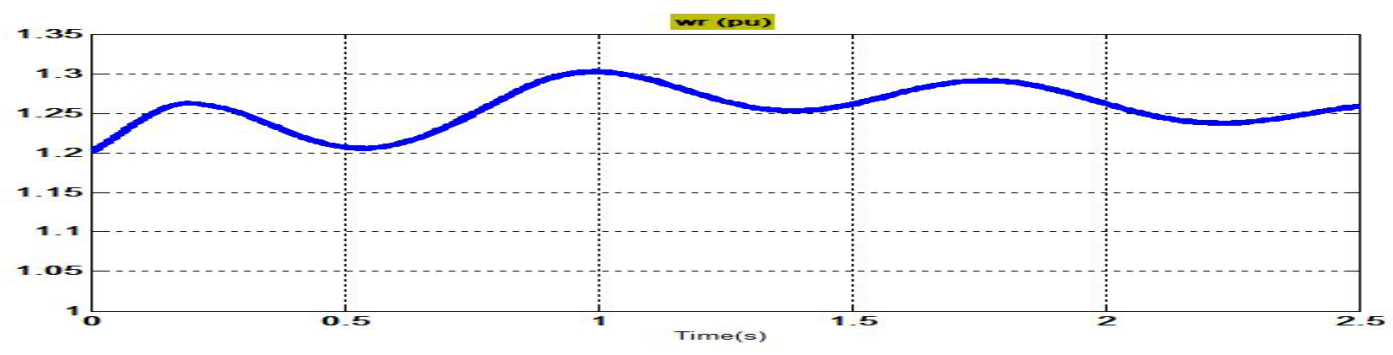

Figure 9. Rotor speed (pu) of wind turbine

\section{Comments and discussions:}

Several tests have been out to study the performance of the machine in both: without and including filter. We note that the DC voltage Vdc of continuous bus is between 1140 and $1160 \mathrm{~V}$ DC and adding filters actually improves the quality of this tension and has increased its average value (see Figure 4 and Figure 8).

Figure 2, 3, 5, 6, 7 and 9 represents the active, reactive power and rotor speed before and after adding the filter. From graphs we can clearly see the presence of different harmonics in the wind farm due to power electronics devices. The graph is representing the noise and presence of harmonics due to same. 
We find that the second channel with filter will perform better because it is this power that will be transmitted to the inverter to power the load or injected to the network.

\section{Control strategy of the Doubly-Fed Induction Generator -}

To adequately control the electricity production of the wind, we will realize independent control of active and reactive powers Ps and Qs stator. The reference $(\mathrm{dq})$ is oriented so that:

$$
\emptyset_{\mathrm{q} s}=\emptyset_{\mathrm{s}} \text { and } \emptyset_{\mathrm{q} s}=0
$$

Assuming that the stator flux $\Phi_{s}$ is constant (constant electric network) and ignoring the stator resistance, we obtain for $P_{s}$ and $Q_{s}$ :

$$
\begin{aligned}
& \mathrm{P}_{\mathrm{s}}=-\mathrm{v}_{\mathrm{s}} \frac{\mathrm{M}}{\mathrm{L}_{\mathrm{g}}} \mathrm{i}_{\mathrm{qr}} \\
& \mathrm{Q}_{\mathrm{s}}=-\mathrm{v}_{\mathrm{s}} \frac{\mathrm{M}}{\mathrm{L}_{\mathrm{g}}} \mathrm{i}_{\mathrm{dr}}+\frac{\mathrm{V}_{\mathrm{s}}{ }^{2}}{\mathrm{~L}_{\mathrm{g}} \omega_{\mathrm{g}}}
\end{aligned}
$$

The currents $\hat{i}_{\text {qr }}$ and $\hat{i}_{\mathrm{dr}}$ are such that:

$$
\begin{aligned}
& \mathrm{u}_{\mathrm{dr}}=\mathrm{R}_{\mathrm{r}} \mathrm{i}_{\mathrm{dr}}+\left(\mathrm{L}_{\mathrm{r}}-\frac{\mathrm{M}^{2}}{\mathrm{~L}_{\mathrm{s}}}\right) \frac{\mathrm{di}_{\mathrm{dr}}}{\mathrm{dt}}+\mathrm{g} \omega_{s}\left(\mathrm{~L}_{\mathrm{r}}-\frac{\mathrm{M}^{2}}{\mathrm{~L}_{\mathrm{g}}}\right) \mathrm{i}_{\mathrm{qr}} \\
& \mathrm{v}_{\mathrm{qr}}=\mathrm{R}_{\mathrm{r}} \mathrm{i}_{\mathrm{qr}}+\left(\mathrm{L}_{\mathrm{T}}-\frac{\mathrm{M}^{2}}{\mathrm{~L}_{\mathrm{g}}}\right) \frac{\mathrm{di}_{\mathrm{qr}}}{\mathrm{dt}}+\mathrm{g} \omega_{s}\left(\mathrm{~L}_{\mathrm{T}}-\frac{\mathrm{M}^{2}}{\mathrm{~L}_{\mathrm{g}}}\right) \mathrm{i}_{\mathrm{qr}}+\mathrm{g} \frac{\mathrm{MV}_{s}}{\mathrm{~L}_{g}}
\end{aligned}
$$

We can then establish the block diagram of the machine [4]:

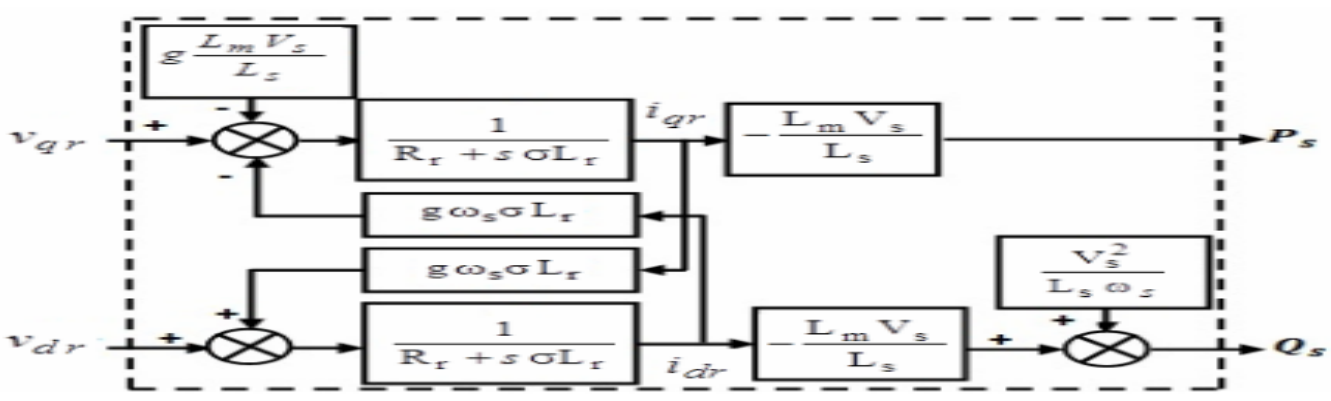

Figure 10. Bloc diagram of the generator

The powers and the voltages are linked by a first order transfer function. Since the slip value is weak, it is possible to establish a vector control, because the influence of the coupling will remain weak and their own regulators can control the $\mathrm{d}$ and $\mathrm{q}$ axes separately. [1]

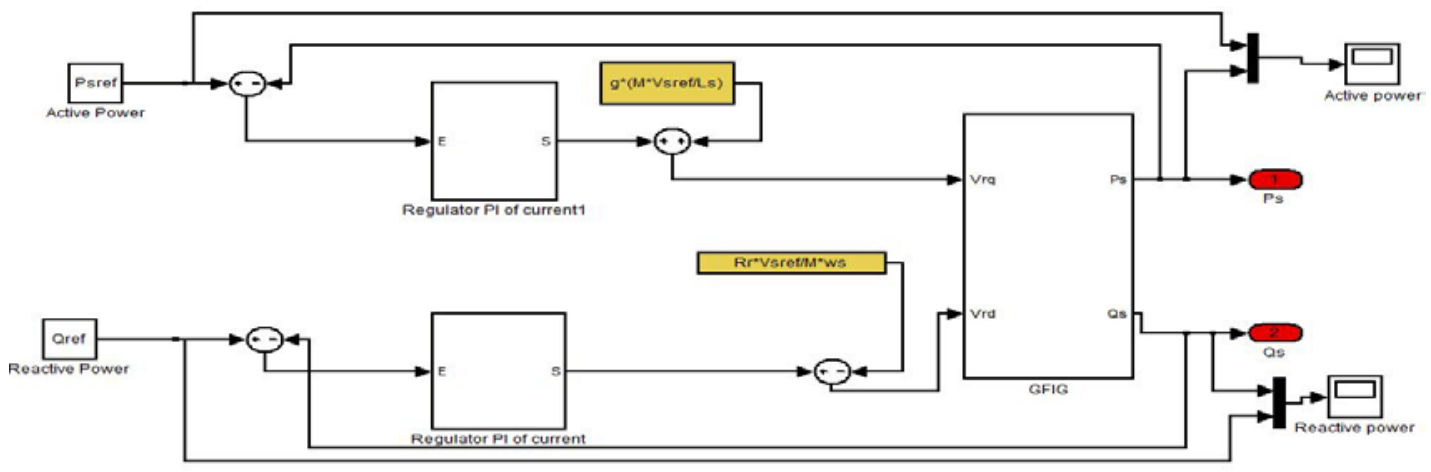

Figure 11. Direct vector control with classical regulator PI 


\section{Fuzzy control -}

One can solve the problem of the parameters, which lead to influence to the performance of the system and even instability of it in extreme cases, by adapting the fuzzy control techniques where the regulator adapts to the operating conditions of the system.

Fuzzy logic is a new method that has been introduced on a large scale in JAPAN, more recently it is more and more applied in Europe [8, 10].

The internal structure of the control by the fuzzy logic consists of three blocks: Fuzzification, Inference, Defuzzification.

After several simulation tests, we have chosen for the fuzzy controller a partition of speech universe with five fuzzy sets: NG (negative big), N (negative), Z (Zero), P (positive), PG (positive big). Each fuzzy set is represented by either triangular membership function or trapezoidal membership function [10].

Simulation is done to illustrate the fuzzy control performances applied to the DFIG. A bloc diagram is proposed in Figure 12 to control the system.

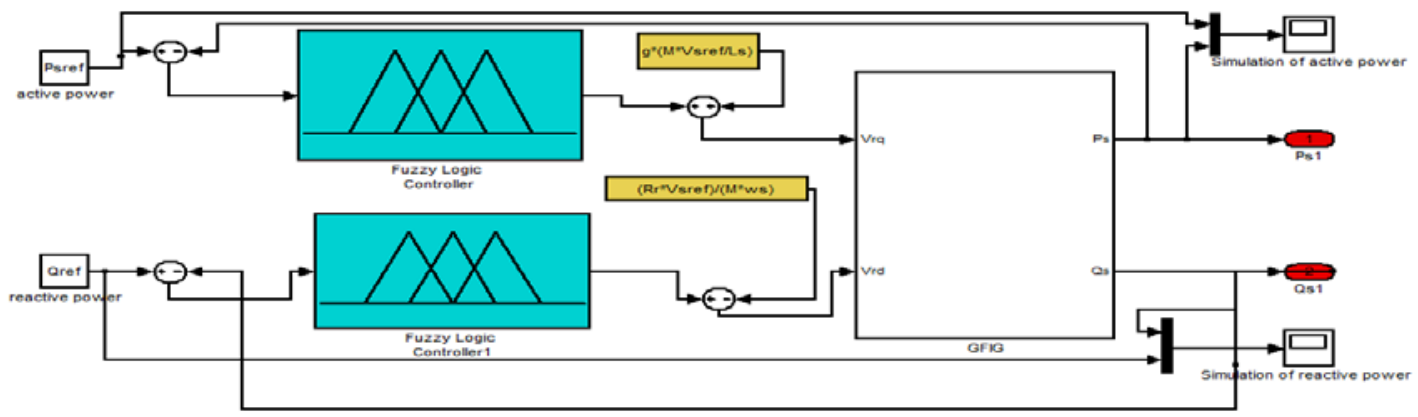

Figure 12. Diagram of the fuzzy controller of the reactive stator power

\section{EXPERIMENT AND RESULT}

For studying dynamic behavior of proposed system based on fuzzy logic controller and classical PI controller, some different situations and events are considered.

We have subjected this system to many different value of active and reactive power in order to observe the behavior of its regulation and to prove the capability of the fuzzy controller.

The Doubly-Fed Induction Generator studied is characterized by the parameters given in table 1:

Table -1 Generator settings

\begin{tabular}{|c|c|c|c|}
\hline Rotor resistance & $0.016 \Omega$ & Number of pairs of poles & 3 \\
\hline Rotor inductance & $0.16 \mathrm{H}$ & Stator resistance & $0.023 \Omega$ \\
\hline Mutual inductance & $2.9 \mathrm{H}$ & Stator inductance & $0.18 \mathrm{H}$ \\
\hline Resistant couple & $0.1 \mathrm{~N} . \mathrm{m}$ & Single voltage of the network & $575 \mathrm{~V}$ \\
\hline
\end{tabular}

The direct method with a classical regulator (PI): 


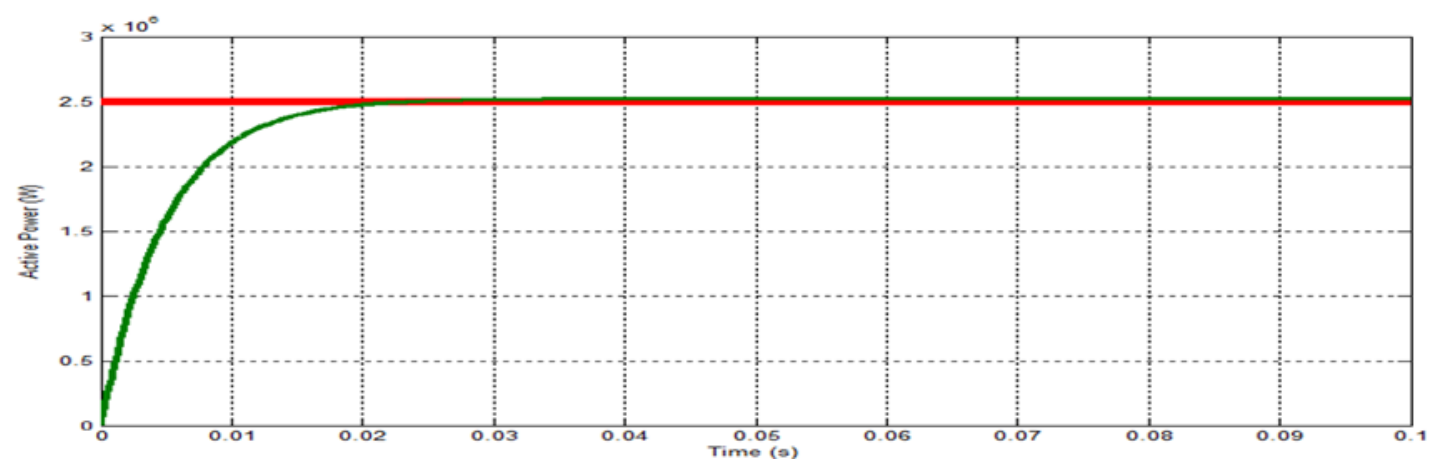

Figure 13. Active stator power with reference $P_{s}=2500 \mathrm{Kw}$

The direct method with a fuzzy regulator:

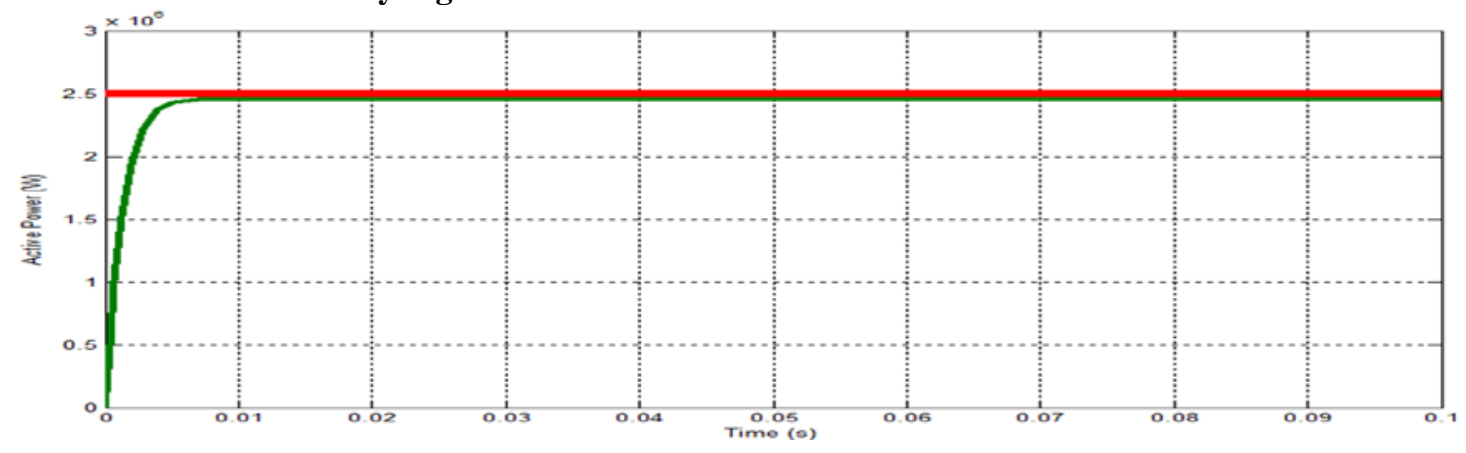

Figure 14. Active stator power with reference $\mathrm{P}_{\mathrm{s}}=2500 \mathrm{Kw}$

The results plotted in the following figures show the powers generated when reference signals are applied.

Fig. 13 shows the answers with classical PI and Fig. 14 shows the answers with fuzzy controller.

The active power follows the desired variable. In fuzzy logic control, the answer is without overshoot, no coupling effect; the static error goes to zero, rapid in transient state.

During the fault, we have a little change in active and reactive power of wind turbine and in other parameters such as rotor and stator resistance and inductance, mutual inductance, number of pairs of poles and single voltage.

\section{IV.CONCLUSION}

In this paper, we studied the modeling and the control of the Doubly-Fed Induction Generator and analyzed two different control systems. First, a generator model is proposed; then, a control strategy using fuzzy logic of the DFIG allowing an independent control of the powers is also proposed. The results show the improved quality of the control when using the fuzzy logic controller. Through the response Characteristics, good performances are observed even in the reference signal variations. The output power follows the reference signal without overshoots.

The advantages of the fuzzy control are that it is parameter insensitive, provides fast convergence, and accepts noisy and inaccurate signals. The fuzzy algorithms are universal and can be applied retroactively in any system. System performance, both in steady state and dynamic conditions, is excellent.

\section{REFERENCES}

[1] K. M Ouilah, M.Abid, A. Naceri, M. Allam, "Fuzzy Control of a Doubly Fed Induction Generator for Wind Turbines”, in JEE, Algeria .

[2] A. Boyette, "Controlling a doubly-fed asynchronous generator with storage system," Ph.D. thesis, university Poincaré, Nancy, 2006.

[3] A. Wahabi, A. El Moudden, F. E Bounifli, A. Aarib , " Improved performance of a wind energy conversion chain driven by an asynchronous generator doubly fed by a "RL" filter ", In IJECCE, Vol. 6, 2015.

[4] F. Poitiers, " Etude et commande de génératrices asynchrones pour l’utilisation de l'énergie éolienne ", Ph.D. thesis, univ. Nantes, 2003.

[5] A. El Moudden, A. Wahabi, A.Sandali, F.E Bounifli, " Modeling and simulation of a double-fed asynchronous generator for control of wind energy ", International Congress of Thermal, Morocco, 2014.

[6] A. El Moudden, A. Wahabi, A.Sandali, F.E Bounifli, " Control and optimization of the energy produced by a chain of wind energy conversioncontrolled by a doubly-fed asynchronous generator ", in CTTS, Vol. 3, 2014. 
[7] A. El Moudden, A. Aarib, A. Wahabi, F.E Bounifli, " Command of the active and reactive stator powers of the doubly fed induction generator used in wind energy ", in IJETAE, Vol. 4, 2014.

[8] A. Tamaarat, " Modélisation et commande d'un système de conversion d'énergie éolienne à base d'une MADA ", Ph.D. thesis, university Mohamed Khider, Biskra, 2015.

[9] T. Tagaki, M. Sugeno, " Fuzzy identification of systems and its applications to modeling and control MADA ", in IEEE, 1985.

[10] F. E. Bounifli, A. El Moudden, A. Wahabi, A. Hmidat, " Vector control of a Doubly-Fed Induction Generator by using a classical PI and a fuzzy PI controllers ", in WJIR, Vol. 1, 2016. 